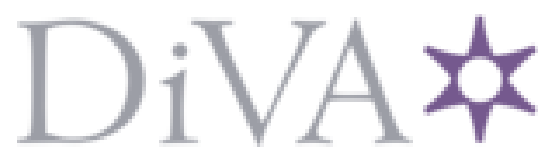

http://www.diva-portal.org

This is the published version of a paper published in International Journal of Web Based Communities.

Citation for the original published paper (version of record):

Reneland-Forsman, L. (2013)

Students' web-based actions when linking theory and practice.

International Journal of Web Based Communities, 9(4): 448-464

Access to the published version may require subscription.

N.B. When citing this work, cite the original published paper.

Permanent link to this version:

http://urn.kb.se/resolve?urn=urn:nbn:se:Inu:diva-29056 


\title{
Students' web-based actions when linking theory and practice
}

\section{Linda Reneland-Forsman}

\author{
Department of Pedagogy, \\ Linnaeus University, \\ 35195 Växjö, Sweden \\ E-mail: linda.reneland@lnu.se
}

\begin{abstract}
This study used representational affordances of IT to trace meaning making as the semiotic actions of training teachers in a web-based educational practice. Eighteen weeks of asynchronous communications were analysed using mediated discourse analysis. Results showed a process orientation in communication. Students were exposed to a variety of experiences and opinions, helping them to find ways to relate to theory. The link between theory and practice was helped by strategies as: 1) building upon the collective - from I to we; 2) introducing a cultural or historical shift; 3) making 'different' known and shared by the group; 4) revisiting earlier established concepts from the course. Results point towards the importance to address design aspects of working with the impact of other's represented experience and 'distance' as representations of actions providing distance to self, practice and thought as pedagogical aspects of the web-based environment.
\end{abstract}

Keywords: collaboration; meaning-making; mediated discourse analysis; MDA; participation; professional training; student strategies; higher education; web-based education; theory and practice.

Reference to this paper should be made as follows: Reneland-Forsman, L. (2013) 'Students' web-based actions when linking theory and practice', Int. J. Web Based Communities, Vol. 9, No. 4, pp.448-464.

Biographical notes: Linda Reneland-Forsman is a Senior Lecturer at the Linnaeus University, Sweden. Her thesis (2009) 'A changing experience communication and meaning making in web-based teacher training' focused the influence of meditational means for student learning and meaning making processes. She is currently studying the influence of academic disciplinary discourse for integrating ICT in HE.

\section{Introduction}

Professional training in $\mathrm{HE}$ is often criticised for not being able to link professional practice and theory through a critical and scientific approach. Students and practitioners often relate theory and theoretical concepts to research and research criteria, whereas practice is related to the everyday activities at a workplace (Schön, 2002). This study shows that the choice of strategy mattered for adjoining theory and practice. The way students collaborated mattered for how their insights developed. 
This study explores the asynchronous communication of 55 students in using experience and other practices outside the course context to make meaning within course context during 18 weeks of assignments, lectures and reading course literature

\section{Background}

Dewey (2004/1916) believed that knowledge, as absorbed in the formation of human character through social interaction, was threatened by the institutionalisation of learning but argued that the experience of others is possible to share and make common through communication, and thereby affect the dispositions of others in a relationship between experience and thinking. Meaning, he meant, is constituted in the process of communicating experience and thought, which makes communication a constitutive for pedagogy. A web-based educational practice offers this sought for insights into student sharing of experiences and their knowledge-building processes since communication is registered and possible to re-visit. From a pragmatic and relational perspective on knowledge, I have tried to follow how students try to make meaning within a course context in asynchronous peer-groups. The concept of meaning is here based on an intersubjective approach to meaning where meaning represents a direction in action based on the experiences, knowledge and the cognitive structures students use to face a new situation or information.

Växjö University (now Linnaeus University, Sweden) gave a 4-year, 180-credit (ECTS) part-time programme, where the child minder category was trained for preschool class. The programme used a virtual learning environment (VLE) with additional three physical meetings each semester. When the students started the programme, they had substantial experience of working in preschools, but little or no experience of higher education or ICT-supported environments. At the start of the study, students were two years into the programme, facing completely new working group constellations based on the teachers didactical considerations.

\section{The study}

Data is from a PhD study (Reneland-Forsman, 2009). Students in the programme studied were all women, working as child-minders. Courses were designed to make use of their previous experiences and teachers stressed that experience was not confided to professional experiences.

Data consists of the asynchronous communication of ten groups, 55 students during two courses (18 weeks) of a web-based teaching programme (Table 1). The two courses were aimed at students developing knowledge necessary to identify with and understand how cultural identities and the living conditions of young children are created and formed by different contexts. Figure 1 shows where in the programme the two courses were placed (during the third year of training). 
Table 1 Showing the number of postings by individuals and teachers during the two courses, (18 weeks)

\begin{tabular}{lcccccccc}
\hline Group & Ind 1 & Ind 2 & Ind 3 & Ind 4 & Ind 5 & Ind 6 & Teacher & Total \\
\hline 1 & 135 & 185 & 120 & 137 & 122 & 102 & 2 & 801 \\
2 & 96 & 171 & 117 & 94 & 100 & 40 & 1 & 619 \\
3 & 119 & 108 & 110 & 103 & 39 & - & 2 & 481 \\
4 & 107 & 76 & 76 & 75 & 44 & - & 3 & 381 \\
5 & 76 & 112 & 82 & 63 & 9 & - & 3 & 345 \\
6 & 92 & 51 & 80 & 109 & 114 & - & - & 446 \\
7 & 67 & 44 & 60 & 42 & 45 & 59 & 1 & 318 \\
8 & 60 & 50 & 54 & 46 & 42 & - & 1 & 253 \\
9 & 60 & 96 & 50 & 48 & 46 & 84 & 7 & 391 \\
10 & 79 & 116 & 89 & 86 & 95 & - & 3 & $468 / 4,503$ \\
\hline
\end{tabular}

Figure 1 Shows course placement within the programme (see online version for colours)

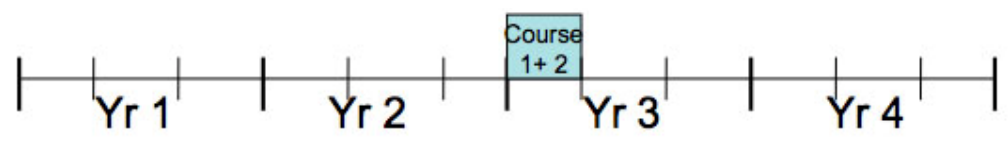

Both individual and group assignments were used, sometimes in combination, together with parallel self-evaluation methods, both individually and in groups. Individual assignments always included a social element.

Figure 2 Shows how group and individual assignments were spread over the courses

Course 1

- - - -Continuous individual logbook - - -

\begin{tabular}{|c|l|l|l|l|l|l|}
\hline $\begin{array}{l}\text { Discussion }+ \\
\text { Group synthesi\$ }\end{array}$ & & $\begin{array}{l}\text { Discussion + } \\
\text { Individual paper }\end{array}$ & & $\begin{array}{l}\text { Individual + } \\
\text { Group assignment }\end{array}$ \\
\hline
\end{tabular}

Course 2

- - - - Continuous individual logbook - - -

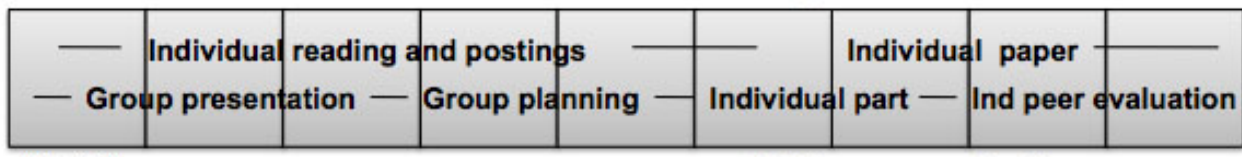

Week 10

Week 18

To improve web-based courses, several studies on web-based collaboration and student strategies had been conducted for these programmes and the results were communicated to new students. Among these results were the importance to form a group culture and a common base for knowledge building when collaborating online but also the responsibility they all shared for each other's progression (see Ahlbäck and Reneland-Forsman, 2005; Reneland-Forsman and Ahlbäck, 2007). 


\subsection{Methodology}

This study is inspired by Deweyan pragmatism and mediated discourse analysis (MDA) to obtain an intersubjective and contextual view of self and society. The intersubjective production of meaning is an element of the social at many levels and visible as:

- ways of acting

- ways of representing

- ways of being (Fairclough, 2004).

MDA has most importantly been chosen for its broader representation of action and for how it fills the gap between the study of communication and the recipients' reaction, which capture the intersubjective character of the web-based dialogue (see Jones, 1998; Kress, 2004; Scollon, 1998, 2001, 2005, 2008; Scollon and Scollon Wong, 2004).

Drawing from Dewey, with meaning constituted in the process of communicating experience and thought, action and its influence on students' forthcoming actions and focus becomes the object of study. Actions are here taken in digital settings which means an exploration into technology-mediated online communication, an analysis of what happens on the screen going beyond the traditional notion of text (Kress, 2003).

Communication according to Dewey (2004/1916) is to be understood as a process of sharing experiences until they become common goods. It is only when common goods are shared and acknowledged by all participants that dispositions might transform (Dewey, 2004/1916). Reification is used to identify this process of becoming 'common goods', describing a process pointing to a shared focus in practice - when something becomes the point of orientation of the mediated actions of the students. The representational aspect of reification is of analytic value in this study in identifying, when a phenomenon becomes accessible for reflection and is thereby shared. Loose fragments, senses and ideas find their way into abstract concepts.

Analysis was done in two steps

- as the identification of semiotic actions (Table 2)

- and finally the construction of themes based upon actions.

The concept of mediational means is used in analysis for identifying means for carrying out human actions. MDA takes help from ethnomethodology in searching for taken-for-granted routines, emerging rules and unspoken meanings as embodied know-how. Ethnomethodology makes a point of the lack of control of end results in communication. People act without having the end result in mind, adjusting actions as they go along by referring to what is culturally legitimate (Miettinen, 2006). Mediational means are both physical and psychological and mediate between agents and their social worlds and can both amplify and restrict social action (Jones and Norris, 2005). This means that meditational means are both explicit functional aspects of the electronic environment such as discussion threads or subject lines but also implicit, e.g., in terms of how you choose to present/introduce a posting to a conversation or intervals between postings.

The concept of 'nexus' is used to identify what other practices seems to be interfering in communication since web-based education makes its way into people's lives on a different basis than regular education. A traditional thick description of context 
associated with ethnography is difficult to achieve online. But MDA provides the concept of nexus of practice instead, which helps unravel the mix of interfering practices.

Sites of engagement are here used to focus space for intersubjectivity. Norris and Jones (2005, p.139) describe sites of engagements as "a real time window opened through the intersection of social practices and mediational means that enables a mediated action to occur". Actions occur on these sites and some are given preference before others depending on which windows are presently opened. The sites indicate orientation in time and space of occurring mediated social actions. However it is important to bear in mind that sites of engagements vary from individual to individual in time and space (Scollon, 2005). Here, it is the possible sign of converging sites that is interesting to identify in this study.

The semiotic actions are manifestations in language carrying meaning. Semiosis are part of action as humans act and interact through speaking or writing. Semiosis also figures in social practices as representations, e.g., of the material world, of other social practices and reflexive self-representations of the practice in question (Fairclough, 2004).

The semiotic actions identified in Table 2 are empirical following an exploratory approach to communicative actions.

Table 2 Showing semiotic actions identified

\begin{tabular}{|c|c|}
\hline Type of action & Expressed as \\
\hline Non-action & Silence, avoidance \\
\hline Acts of 'pointing' & References \\
\hline Declarations & $\begin{array}{c}\text { Acts of presence, interest, expectations, promises, ambitions, rhetoric, } \\
\text { personal views }\end{array}$ \\
\hline Deliveries & $\begin{array}{l}\text { Drop-offs expected by peers and teachers (observations, reflections, } \\
\text { conclusions, confidences, answers, questions, arguments, definitions, } \\
\text { contextual cues, introductions) }\end{array}$ \\
\hline Challenges & Invitations, openings, questions, regrets, rejections \\
\hline Confirmations & Acknowledgments, concerns \\
\hline Closures & Agreements, changes of subject, signing-offs \\
\hline
\end{tabular}

Four themes emerged from the material as clusters of meaning making processes of students relating to course objectives:

- Participation, actions oriented towards an active manifestation of presence, engagement in course work - a commitment to task, and the creation of space for engagement.

- Positioning, actions oriented towards the creation of a student identity, the organisation of work, and the construction of a group culture

- Reference as the orientation actions took in a nexus of practices. Where did students go to try out and challenge theoretical concepts? Or to mirror their existing views and knowledge?

- Changing experience is a collection of moments of reification, when students came to make realisations of relevance to subject and task - resulting in an elaborated experience. 


\subsection{Findings}

How communication came to develop was the result of a complex web of interactions. Often communication started by a seemingly 'empty' posting without specific references or content, postings possible to write without reading the course literature but delivering signs of presence, making the discussion look active and alive (see Reneland-Forsman, 2012).

Discussion threads differed when you studied their impact on students' meaningmaking. There were postings of an affirmative character, looking for reinforcement, as well as problematising and rhetorical postings. Most groups however, managed to take discussions to a challenging and contributing level at some stage.

\subsubsection{Signs of a Nexus}

In terms of practices, students explicitly oriented themselves in language towards:

- the field of education

- the context of the university programme

- $\quad$ parenting as supplying experience

- $\quad$ parenting as things diverting their focus

- being a student

- $\quad$ preschool specifically as their own everyday practice

- $\quad$ preschool generally - as a field of practice

- preschool generally - as research

Changing from talking about preschool specifically to talking about preschool generally as a field of practice or field of research seemed to be a critical point in communication. When new themes were introduced in the discussion, students often started by associating to their own children or a specific situation or routine at their preschool. Some groups could spend many postings supplying examples from their everyday practice.

\subsubsection{A phase of confirmations}

Continuous confirmations or an unwillingness to change views was seldom present as whole threads in discussions. Exchanging personal views could often characterise the start of a discussion though, and occasionally also the outcome, depending on how experiences and course literature were used in the process.

This quotation finished a 200 -word posting only vaguely related to an article (the student could in fact just have responded to the heading).

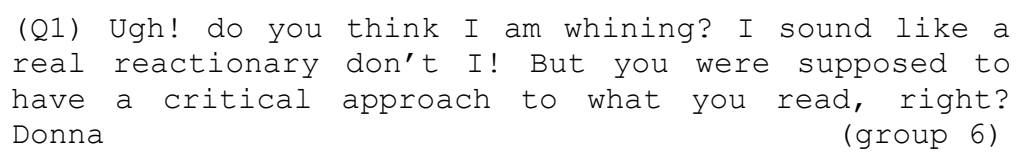


Let us use this as an example, taking a start in personal experiences and opinions common in the early days of communication on an assignment. When supposed to comment on articles, Donna only delivered strictly personal statements. There was no self-criticism in sight. It looked as if she was after affirmation and used what she had perceived as a key concept in the course, namely 'critical thinking'. She did, however, not apply the concept on her own perspective. This group (nr 6) continued to make plenty of personal declarations but few references. When the group realised that it was time to think about the end product they had produced over 40 postings stating mainly personal views. There were some associations to the themes in the study guide but only generally mentioned. This group seemed to have its focus elsewhere. They spent a longer than average time on just 'showing up' online, dropping declarations that represented presence, filled the space and created a sense of activity but this site of engagement was not fully opened (see Reneland-Forsman, 2012). You can almost feel that they awaited someone's initiative. For this group discussions never had time to change from mainly making parallel declarations or confirmations and their end-product in many respects came to build upon a comparison with each other (see Reneland-Forsman and Ahlbäck, 2007). They had not yet formed the common ground necessary for taking on what was presented to them through the course and present a synthesis.

\subsubsection{Introducing a perspective}

The process of making a phenomenon accessible for reflection and thereby shared and reflected upon by the whole group often started as loose fragments, senses and ideas that found their way into abstract concepts accessible for reflection. The different ways this took was embedded in long threads facilitating a panorama over their common knowledge, experience and personal opinions

\subsubsection{From I to we - building upon the collective}

Building upon the concept of 'we' instead of 'I' proved to be one way for the groups to introduce a perspective. Together groups managed to put some distance between themselves and the practice where they worked and might have worked for many years. For many individuals this was difficult to achieve on their own. When starting to talk about themselves in terms of 'we' instead of I, students managed to unite with other group members although not always agreeing. That was one of the ways in which the group came to represent a community of what was agreed upon as known and familiar to them. Together they could undertake what was new and 'different'. With 'we' followed a broader platform than 'I', from which the students could explore and deepen their understanding as individuals and as a collective.

Some groups used longer periods for holding on to personal views. In this next example, students wrote anecdotes, adjoining in 'sameness', but not ready to reflect upon 'different'. Their discussions had problems to take-off. The example deals with the concept of parents constantly negotiating with their children mainly by referring to the articles constituting course literature followed by a contrasting personal opinion. You sense some discrepancy between views represented in literature and this student's personal views. You sense an opinion that children who speak their mind take up too much space and might fall into the habit of talking back. 


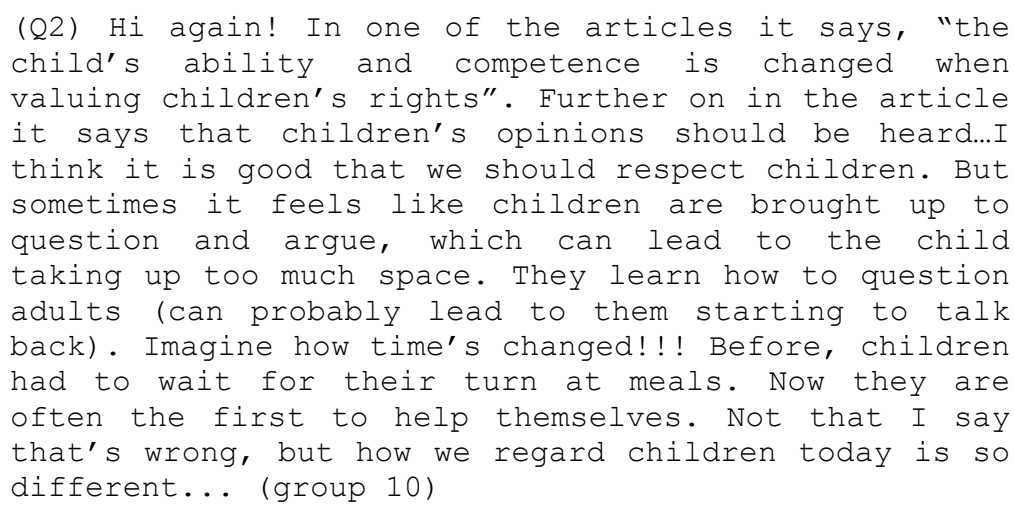

Her view was shared and confirmed by the next 'speaker', but the orientation of the thread changed two postings later:

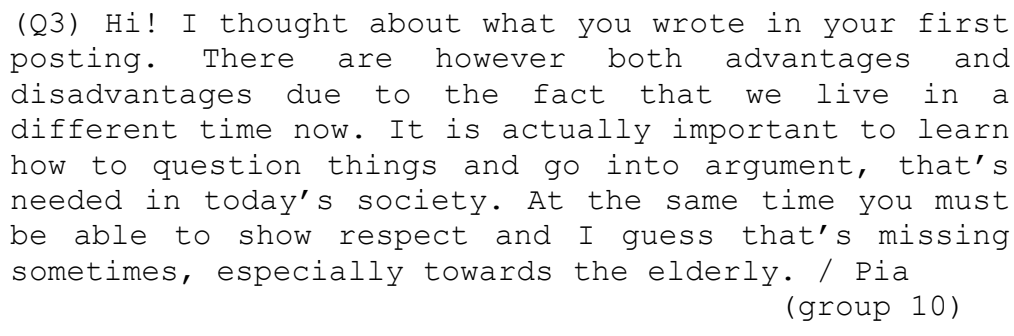

Pia moved through the nexus of practices accessible to her and presented her arguments from a different perspective. This change of perspective was accomplished by relating the concept of 'talking back' to a societal level instead of to everyday preschool practice. She addressed 'talking back' as a necessary competence in a future society. As such the group could continue to discuss the competence of 'talking back' as being a concern for preschool and school activities and addressed by curriculum. She finished though, by acknowledging the first student and her opinions as being about the lack of respect, something she too could identify with. This student's questioning and support created a 'we' in at least one respect (we who think it is important that children show respect). Being seen and respected in her view of things might have made it easier for the first student to reflect upon her own statements from the new perspective that Pia introduced: What kind of competence is talking-back in a societal perspective?

In another example, students were to discuss articles on gender but got stuck in presenting examples of gender stereotypes using their own children and their social networks. Then a student delivered a 768 -word posting inspired by the gender texts. She summarised articles, presented highlights and referred to the subject as a general issue for preschool by introducing a societal perspective.

This student performed a significantly important semiotic action. At the end, she pointed to a rather provocative example of preschool staff behaviour described in an article. She could have ascribed this apparently unwanted behaviour to preschool teachers as a category. In such a case they, as child-minders, could have conveniently formed an opposing category, not the one criticised by the author of the article. But she did not act in this direction. Instead she included herself and her peers in the category being criticised by using specific and general examples where she applied self-reflection and 
self-criticism. A couple of hours later a peer confessed to this self-appointed critic by writing:

It went about the same way as usual when we pedagogues want to have some peace and quiet...

\section{Using a historical or a cultural shift}

There were several examples of how focus changed after one student introduced a historical perspective. Here is that same repetition of stories from everyday practice based upon personal opinions, just adding examples of parents today doting on their children. One student then moved the problem to a historical context by using the course literature and introduced a different angle of approaching the phenomenon of 'curling parents' to her peers:

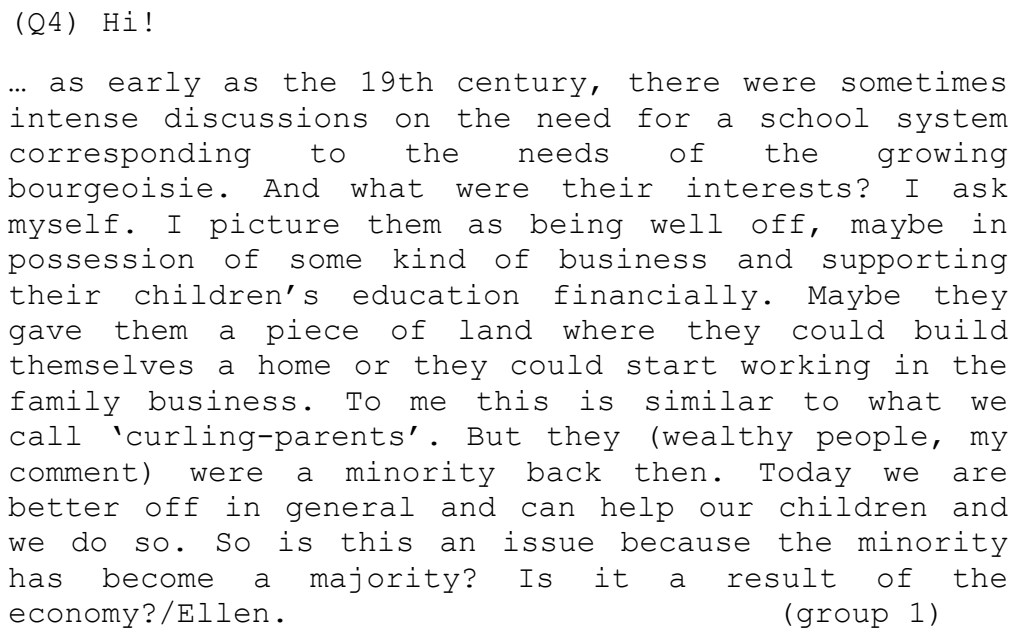

This take-off from what seemed to be an inability to raise the horizon from everyday practice immediately had an effect on the other students. In this case, everyday practice had previously only been used to confirm personal opinions.

(Q5) Hi !

When you Ellen describe how things used to be I realise that you could call that a sort of 'curling' but I haven't thought about it that way. It is probably the way you describe it, that they were a minority and now we are all better off.//Marie. (group 1)

(Q6) Hi,

I also find this an interesting thought Ellen! I haven't thought about it that way, so that was a new, fresh idea. It is always fun when someone finds something new, not spotted by anyone else. That's what's so good about this program I think, since we all work with the same things and you get a lot of fun and interesting hints, ideas and new ways of thinking! Kind regards K. (group 1 ) 
The next example of a take-off is from group 1. A student made reference to a text and the concept of 'normal' and then oriented herself towards what she interpreted as signs of being normal in today's society, maybe to test her own understanding of what the authors wrote about normality. She pursued her own understanding and shared an example she had experienced as a parent that she thought was related to 'normality'. Another group member took up the thread the next morning. Her posting seemed to take off from an established base in everyday practice and her own experience as a parent to take on a societal and cultural perspective. She then returned to consequences for practice.

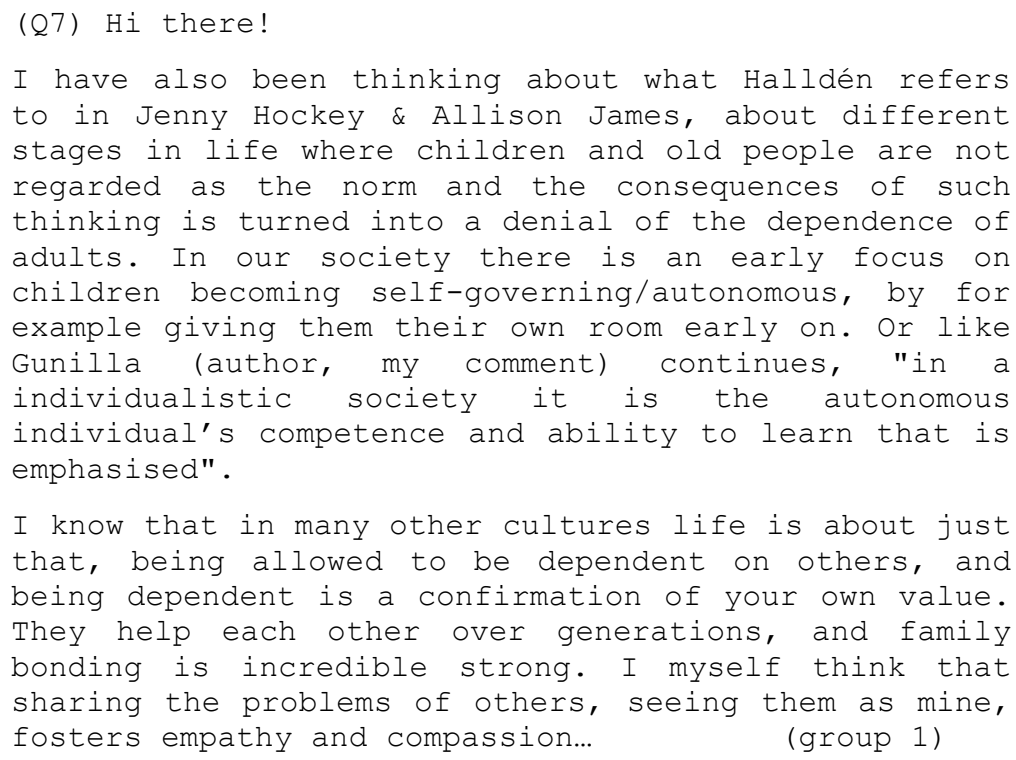

\section{Turning 'different' into 'known' and 'shared'}

Let us go back to group 10 (quotes $2 \& 3$ ) that had got stuck in expressing personal opinions on children 'talking back' and 'taking up space' in everyday practice. Pia had planted the idea of 'talking back' as a necessary competence in today's society. A competence being of their professional concern seemed to be her unspoken meaning. She tested her idea against the literature and returned a couple of hours later with a reference to the curriculum and how it discussed competence and the participation of children in everyday practice. She:

- delivered a reference to a page in a comment to the curriculum where the question of children's participation and influence at school and preschool were being discussed

- delivered an example from her preschool about what was done there

- $\quad$ pointed towards practice again by problematising the differences between policy and practice (the lack of time)

- $\quad$ pointed towards curriculum with a reference to where the role of the preschool for children's trust in their own ability could be found

- delivered suggestions about how these competences could be stimulated in small children 
- referred to how the curriculum wants this work documented

- delivered a compromise on how this could be achieved in practice, despite constant lack of time, together with an argument why this is necessary work to do.

With these two postings she had created sameness between her opinions as a group member and policy documents. Being a member of a group her sameness came to work as an offer for the whole group and contribute to a common platform for the group to expand their views and discussions. Two days later the student who started the thread on 'talking back' replied:

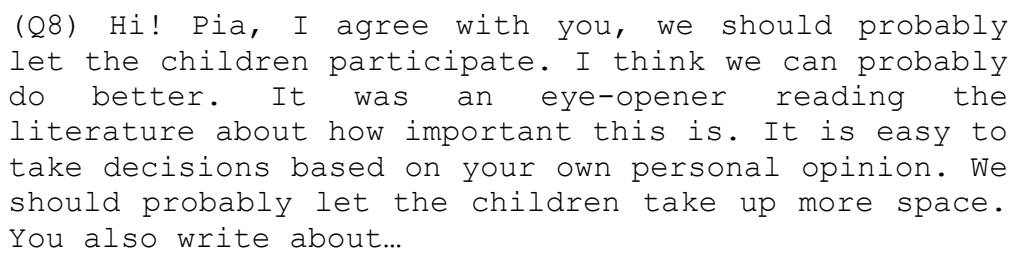

\section{Revisiting previous course concepts}

Finally, the process of revisiting previous established understandings of concepts in the course were visible, mostly during individual assignment periods. Students encountered articles that seemed to have added to or changed their experiences and with the help of stored previous discussions they could pick up and elaborate their understanding.

\section{Individual assignment processes}

Moments of reification were possible to study also during individual assignment periods, since individual assignments all had an element of social to them (see Figure 2).

Communications slightly differed by comparison though. Students used postings either to express personal opinions or to summarise articles. Presenting summaries introduced a monological character to communication. Postings supposedly just showed ambition and presence and contained fewer categories of actions.

Sometimes this monological form was broken and the delivery of personal experiences and views, were exchanged for other actions. A structuring posting often seemed to help the others to approach a subject and stop encircling as often the result of a summary.

\subsubsection{Process and products}

The character of communication showed signs of a process-oriented communication. The students had 20 days to produce the first group assignment. Table 3 illustrates how many postings were made before students first mentioned the assembling of discussions into a paper product. The number of days ranged from 5 to as many as 12 days of discussions before the groups focused their attention explicitly on the group-paper by mentioning the paper or the organisation of working with it. Five groups worked for 10 days or more with the contents before they made any kind of reference to the end product, which is half of the number of days bound for this particular task. 
Table 3 Numbers of postings during group assignments before mentioning end product or organisational aspects of group work

\begin{tabular}{lcc}
\hline Group & No. of postings & No. of days \\
\hline 1 & 60 & 8 \\
2 & 110 & 12 \\
3 & 38 & 9 \\
4 & 29 & 9 \\
5 & 18 & 5 \\
6 & 42 & 9 \\
7 & 35 & 12 \\
8 & 25 & 12 \\
9 & 40 & 10 \\
10 & 56 & 12 \\
Mean & 45.3 & 9.8 \\
\hline
\end{tabular}

\section{Discussion}

I have presented results as examples of the orientations of actions towards change or no change in how students have tackled course content. It was obvious during these periods that the choice of strategy mattered for reification. The way students used each other influenced how their insights developed.

When students failed to distance themselves from everyday practice, only expressing personal opinions, communication often had the character of parallel monologues. Confirmations constituted the interaction and did not help them to distance themselves from personal views and experiences. This is where group interaction became important. Literature supplied alternative orientations but when students failed to see the relevance of other perspectives or practices for the discussion, these other orientations were not included in the students' nexus of relevant practices. Sometimes this difficulty was founded in misunderstandings, bugs in communication or complete lack of understanding of concepts in literature. The relevance of theory was hidden to students.

Experiencing 'the experience of others' became one way of making these missing links of relevance. The fact that colleges, but not themselves, have experienced something made the same thing part of a constitutive process of a professional object of concern to them. Distance seemed significant for taking on course content in a constructive manor. In groups that spent time on negotiating a group culture eventually the sharing of experiences seemed to come easier. And what was shared was possible to include in a common experience using 'we' to take on what introduced by literature. By using the notion of 'we', students managed to unite with other group members although not always agreeing. That was one of the ways in which the group then in terms of 'same', what was known and familiar to them, could undertake 'different'. 'We' became a platform from which students could explore and broaden their understanding as individuals and as a collective. They were also better prepared to take on administrative and organisational obstacles not accounted for in a study guide (see Reneland-Forsman, 2012) 
The fact that students spent a considerable time discussing subject related issues (see Table 3) must be considered worthy of notice and not a probable outcome for campus student seminars. Students were by now two years into the programme aware of the logging of discussions which made it easy to revisit the discussion to see what had emerged as important questions and concepts to include in a report. This easy accessed documentation probably favoured a content discussion over a focus of end product early days of.

\subsection{Design for change}

Only $5 \%$ of the students dropped the programme. The level of interaction was high and evenly distributed. Course objectives were met in a satisfactory way. This is not a story told everyday. In this case course design made a difference.

Today, there is an increasing number of web-based courses where people participate in the pursuit of knowledge and meaning. Students' process of constructing meaning in these courses will undoubtedly be affected by the new conditions for human interaction that come with the environment. The biggest misconception among teachers is that possible success is in the hands of the user when at the same time they have not been invited. Participation anticipates invitation. I have heard teachers say that students never felt the need of using discussion groups. We cannot, however trust the students to choose the best methods for their studying. Mentors are there to make it worthwhile and to act as role models. Appropriate methods should be chosen in accordance with aims and outcomes.

For these courses teachers made an effort of considering the special conditions of the non-embeddedness in time and context of inter-human web-based interaction and the strengths of asynchronous communication. Efforts had been made to support students' understanding of conditions for collaboration and interaction, to which Guribye (2005) ascribes the same importance for the level of success of web-based courses as the production of new knowledge.

The possibility of documenting all communication in the VLE has implications for how lived experience, personal thoughts and values can be used in pedagogical practices. When given space in a course, they can serve as the explicit platform for students. That way lived experience becomes the subject of meta-reflection, adding a quality necessary in courses of a vocational and professional character (see Reneland-Forsman and Ahlbäck, 2007).

The need to create a common ground among students added aspects of shared understanding, which are easily ignore in traditional pedagogical practices. The changed dimension of time and space changes conditions for reflections. The change of reflection prior to action (Sorensen, 1999) might introduce further confrontations with personal values and opinions. There was the representation of elaborated concepts used by peers that students could use for their own development when confronting practice. Sharing presupposes that something is known or graspable to the individual. Keys to how personal opinions and values are formed become accessible to individuals and collectives by discussing and sharing the experiences of others. It is on the basis of one's own experiences that meaning is created in these everyday moments of sharing through social activities (Dewey, 2004/1916). Added to this should be experiencing education as worthwhile. Education then becomes an empowering experience to individuals, and keep feelings of being lost and powerless at a distance (West, 1996). 
The potential powers of communication and dialogical conditions for development and change support these results and should be considered in designing web-based education for which rich interaction and dialogical conditions are not an unconditional effect (c.f. Kreijns et al., 2003; Laurillard, 2002; Mazzolini and Maddison, 2007; Sorensen, 1999).

This study provides enough material to also problematise the concept of support in relation to stimulating interaction among students. There is oppositional debate on whether the participation of teachers stimulates on-line interactions. The question should rather be about what kind of stimulation is requested and how it can be supplied (Sorensen, 1999; Kreijns et al., 2003; Mazzolini and Maddison, 2007; Thorpe et al., 2007). Although not actively participating in these discussions, the teachers managed to establish fruitful circumstances for interaction and the exchange of experiences as a foundation for internalising theoretical concepts and understanding in a form that satisfactorily addresses the requirements of regulations.

Collaborative knowledge building is structured by the intertwining of group and personal perspectives. This does not mean ignoring or fixating upon the role of individual minds, but see them in interaction with group understanding (Stahl, 2002). To design for interaction, not necessarily group work, becomes crucial for the meaning-making and knowledge-building of the whole collective. Collaborative knowledge-building could change the ways students regard their own role for the knowledge-building of others, adding often missing ethical aspects to education, especially important in teacher training.

By focusing on group activities, which necessarily include roles for individuals within the group, and by noticing the importance of artefacts in the world, such as spoken, written or published texts that capture newly constructed knowledge, it is possible to move away from an approach to learning focused on individual minds (Stahl, 2002).

\section{2 'Non-traditional' - the norm of today and the promise for the future}

This study has dealt with students classified as non-traditional (no previous higher education, older than the average student, working while studying, some validated into the programme). Being a non-traditional group, it had many homogeneous elements. The students had all been part of similar educational practices, they had similar backgrounds and were of the same sex and ethnicity. Some of the obstacles involved when trying to experience what others have experienced might be easier to overcome for such a homogeneous group. This raises the question of how diverse a student group can be. When do different experiences contribute and collaborate, and when do they hinder? Or is it a matter of didactical considerations? In encountering 'difference' in terms of theoretical and analytical approaches, the acknowledgment of student experiences throughout the course design seemed to have worked as a springboard for self-reflection. In terms of unfamiliar discourses, interfering working conditions in everyday practice or students' insecurity, the rich and supportive communication created rules and frames for overcoming these obstacles, adding to experience.

Older and more experienced students are important in the learning process and more commonly populating web-based programmes. They are identified as more eager to problematise and criticise (NAHE, 2007). The student population as such contributes to making web-based alternatives more advanced than campus education. This is perhaps 
said as a commendable attempt to balance the talk of distance education as a second best alternative. I would raise a finger of warning, though, and say that this is a possibility but cannot be realised without didactical considerations. Experience is not a guarantee on its own of broader and deeper perspectives but a 'booster', and indeed one of considerable worth. Once again, neither the distribution form nor the student material is in itself a guarantee for the successful outcome of an educational activity.

\subsection{What about men?}

Non-traditional students are moving towards the mainstream of higher education, and as such they have played an important role in changing HE. But so far middle-class students constitute the largest group in comparison with recruitments from groups of lower socio-economic backgrounds (Leathwood, 2005). Women are in majority of students in higher education in several European countries, including Sweden and the UK. University programmes in areas of education, health and care attract many women, while men undertake their vocational training at the upper secondary level (NAHE, 2007).

The question of how these women constructed meaning raises further questions about the meaning-making of other groups. Putting groups of people together and labelling them students, their differences are easily forgotten (Sipos Zackrisson and Assarsson, 2008). A broader recruitment from new professional fields of, e.g., nursing/caring has added to the family of university programmes (Leathwood, 2005). These programmes have a majority of female students and have contributed to changing the gender landscape of HE There are concerns not be connected with the dominating participation of women in higher education but with the diminishing participation of men (Witt, 2008). How can higher education better design for web-based education attracting men? In what way are issues of power and identity and lived experiences of importance in that search?

Finally...

The habituation of managerialism in the field of web-based education has been a quick and simple process since the area of IT and pedagogy is so scarcely populated by pedagogues. Its structures are also gendered with its women students, women teachers in majority, and male IT-support and designers. Along with the growing dependency of market-like conditions for attracting students and contracting research, there are now many new actors making claims and trying to set the agenda for HE. Whose interest will be in focus remains to be seen. This is an important task for pedagogy as a discipline, to take action, formulate questions based on the potential and powers of education, and not to forget investigate and implement the potential.

\section{References}

Ahlbäck, T. and Reneland-Forsman, L. (2005) 'Let's think about it - considering the strengths in web-based teaching', in Chaib, M. and Svensson, A-K. (Eds.): ICT and Teacher Education: Challenging Prospects, Arena, Aldershot.

Dewey, J. (2004/1916) Democracy and Education, Dover Publications, Mineola.

Fairclough, N. (2004) 'Semiotic aspects of social transformation and learning', in Rogers, R. (Ed.): An Introduction to Critical Discourse Analysis in Education, pp.225-235, Lawrence Erlbaum, Mahwah, NJ. 
Guribye, F. (2005) Infrastructures for learning: Ethnographic Inquiries into the Social and Technical Conditions of Education and Training, Department of Information Science and Media Studies, University of Bergen, Bergen.

Jones, R.H. and Norris, S. (2005) 'Introducing mediational means/cultural tools', in Norris, S. and Jones, R.H. (Eds.): Discourse in Action, Routledge, Abingdon.

Jones, S.G. (1998) 'Information, internet, and community: notes toward an understanding of community in the information age', in Jones, S.G. (Ed.); Cybersociety 2.0: Revisiting Computer-Mediated Communication and Community, pp.1-34, Sage Publications, Thousand Oaks.

Kreijns, K., Kirschner, P.A. and Jochems, W. (2003) 'Identifying the pitfalls of social interaction in computer-supported collaborative learning environments. A review of the research', Computers in Human Behaviour, Vol. 19, No. 3, pp.335-353.

Kress, G. (2003) Literacy in the New Media Age, Routledge, London.

Kress, G. (2004) 'Postscript', in Norris, S. and Jones, R.H. (Eds.): Discourse in Action: Introducing Mediated Discourse Analysis, Routledge, Abingdon, Oxon.

Laurillard, D. (2002) Rethinking University Teaching, Routledge, London.

Leathwood, C. (2005) 'Accessing higher education: policy, practice and equity in widening participation in England', in McNay, I. (Ed.): Beyond Mass Higher Education: Building on Experience, pp.17-26, McGraw-Hill Education, Berkshire.

Mazzolini, M. and Maddison, S. (2007) 'When to jump in: the role of the instructor in online discussion forums', Computers \& Education, Vol. 49, No. 2, pp.193-213.

Miettinen, R. (2006) 'Epistemology of transformative material activity. John Dewey's pragmatism and cultural-historical activity theory', Journal for the Theory of Social Behaviour, Vol. 36, No. 4, pp.389-408.

National Agency for Higher Education (NAHE) (2007) What's Quality in Distance Education?, Swedish National Agency for Higher Education, Stockholm.

Norris, S. and Jones, R. (2005) 'Introducing mediated action', in Norris, S. and Jones, R.H. (Eds.): Discourse in Action, Routledge, Abingdon.

Reneland-Forsman, L. and Ahlbäck, T. (2007) 'Collaboration as quality interaction in web-based education', Advanced Technology for Learning, ACTA Press, Calgary.

Reneland-Forsman, L. (2009) A Changing Experience: Communication and Meaning-making in Web-based Teacher Training, Diss. Växjö: Växjö universitet [online] http://urn.kb.se/resolve?urn=urn:nbn:se:vxu:diva-5280 (accessed 06/14/2013).

Reneland-Forsman, L. (2012) 'Towards a broader understanding of social talk in web-based courses. Text \& talk: an interdisciplinary', Journal of Language, Discourse \& Communication Studies, Vol. 32, No. 3.

Schön, D.A. (2002) 'The reflective practitioner: how professionals think in action', TPB, Enskede.

Scollon, R. (1998) Mediated Discourse as Social Interaction: A Study of News Discourse, Longman, London and New York.

Scollon, R. (2001) Mediating Discourse: The Nexus of Practise, Routledge, London.

Scollon, R. (2005) 'The rhytmic integration of action and discourse: work, the body and the earth', in Norris, S. and Jones, R.H. (Eds.): Discourse in Action, Routledge, London and New York.

Scollon, R. (2008) 'Geographies of discourse: toward concretizing the idea of context', Paper presented at the Space, Interaction and Discourse [online] http://www.placeme.hum.aau.dk/conf2008/plenary/scollon.htm (accessed 05/03/2012).

Scollon, R. and Scollon Wong, S. (2004) Nexus Analysis: Discourse and the Emerging Internet, Routledge, New York.

Sipos Zackrisson, K. and Assarsson, L. (2008) 'Adult learner identities under construction', in Fejes, A. and Nicoll, K. (Eds.): Foucault and Lifelong Learning. Governing the Subject, Routledge, London. 
Sorensen, E.K. (1999) 'Intellectual amplification through reflection and didactic change in distributed collaborative learning', Paper presented at the Computer Support for Collaborative Learning (CSCL), Stanford University, Paola Alto, California.

Stahl, G. (2002) 'Rediscovering CSCL', in Koschmann, R.H.N.M.T. (Ed.): CSCL 2: Carrying forward the Conversation, pp.169-181, Lawrence Erlbaum Associates, Hillsdale, NJ.

Thorpe, M., McCormick, R., Kubiak, C. and Carmichael, P. (2007) 'Talk in virtual contexts: reflecting on participation and online learning models', Pedagogy, Culture \& Society, Vol. 15, No. 3, pp.349-366.

West, L. (1996) Beyond Fragments: Adults, Motivation and Higher Education, Taylor \& Francis, Abindon, Oxon.

Witt, A-K. (2008) 'Gender division in sociology degree program - causes and effects?', Paper presented at the Violence and Conflict. 24th Conference of the Nordic Sociological Association, Aarhus, DK. 